\title{
Feminilidade e suas imagens em mídias digitais Questões para pensar gênero e visualidade no século xxI
}

Túlio Cunha Rossi

Introdução

Este artigo resulta de uma revisão teórica e metodológica, aliada às primeiras apreciações do material audiovisual levantado em pesquisa em execução coordenada pelo autor ${ }^{1}$. Propôs-se compreender de forma crítica e aprofundada a construção de imagens do gênero feminino que naturalizariam uma inclinação à afetividade e à emotividade, com ênfase em material publicitário de vídeo circulante em redes sociais na internet. Assim, um dos principais procedimentos da pesquisa consiste na análise de vídeos publicitários disponibilizados no portal de vídeos Youtube e na rede social Facebook, que exploram aproximações entre feminilidade e afetividade, conforme perspectivas hegemônicas e, geralmente, heterossexistas, de gêneros.

A presente reflexão decorre de uma primeira análise mais geral de alguns vídeos levantados para esta pesquisa, combinada a uma necessária revisão metodológica dos problemas, das questões e dos conceitos nela operacionalizados. Trata-se aqui de resultados parciais de uma análise mais conjunta dos vídeos da amostra, identificando recorrências mais imediatas e marcantes como "pontos de fixação", conceito empregado por Pierre Sorlin (1982, p. 230) que indica: "um problema ou um

1. "Amor e sexualidade em construção: consumo, internet e mídias audiovisuais na socialização afetivo-sexual feminina”. Pesquisa vinculada à Universidade Federal do Maranhão (UfMA), com apoio institucional do Departamento de Sociologia e Antropologia e do Programa de Pós-graduação em Ciências Sociais da UFMA 
fenômeno que, sem ser diretamente implicado na ficção, aparece regularmente nas séries fílmicas homogêneas e é sinalizado por alusões, repetições, uma insistência particular da imagem ou de um efeito de construção". Estão previstos no decorrer da pesquisa exames mais pormenorizados de cada vídeo separadamente, levando em conta não somente os pontos de fixação identificados, mas também as diferentes possibilidades e formas que estes assumem, elucidando suas especificidades tanto em relação aos outros vídeos como ao contexto de sua produção e ao meio pelo qual eles são difundidos e recebidos: a internet.

$\mathrm{O}$ artigo está estruturado do seguinte modo: primeiramente, apresentam-se noções fundamentais dentro da temática gênero, enfatizando seu caráter histórico (Scott, 1990), não natural e performativo (Butler, 2013) e ressaltando um esforço de desnaturalização de comportamentos referentes à sexualidade e às relações sociais de gênero como pré-requisito para a análise. A seguir, apresentam-se algumas questões e referências fundamentais sobre análises de imagens em estudos de gênero, problematizando a noção ambígua de representação e sugerindo abordagens que destaquem o aspecto dual da construção das imagens como produtoras e produtos de "realidades"2 sociais. Por último, articulam-se questóes sobre os usos de imagens e vídeos em mídias digitais, marcadas pela interconectividade e instantaneidade, observando desafios que elas suscitam para pensar relações entre imagem, realidade e vida cotidiana e suas implicações em questões de gênero.

\section{Gênero como categoria de análise}

Joan Scott tornou-se referência importante ao problematizar gênero como uma categoria de análise em seus aspectos históricos, discutindo diferentes concepções de gênero dentro da história e das ciências sociais que recaem constantemente no embate entre os determinismos históricos (mais presentes entre simpatizantes do pensamento marxista) e o determinismo biológico. Nesse sentido, as perspectivas de base marxista, embora críticas à naturalização das diferenciações entre gêneros, tendem a substituir a determinação naturalista pela determinação econômica, explicando as diferenças percebidas entre sexos como determinadas prioritariamente pelas condições materiais de existência e relações de produção. A autora também suscita a importância de pensar o gênero articulado a outras categorias de diferenciação social como raça e classe, funcionando, contudo, de modo distinto. Assim, Scott rejeita a

2. Partilha-se da perspectiva de que "a realidade é construída socialmente" (Berger e Luckmann, 1983, p. 11), priorizando aqui aquela considerada "realidade da vida cotidiana" que, segundo os autores, "se apresenta sendo a realidade por excelência” (p. 38). 
paridade entre as categorias classe, gênero e raça, bem como recusa a noção de que as desigualdades de gênero e as ideologias que as reiteram sejam, antes, meros reflexos da materialidade da própria estrutura (Scott, 1990, p. 73).

Fundamentando seu argumento em críticas a diferentes posicionamentos teóricos, Scott estabelece duas proposições centrais: “(1) o gênero é um elemento constitutivo de relações sociais baseadas nas diferenças percebidas entre os sexos; e (2) o gênero é uma forma primária de dar significado a relações de poder” (Scott, 1990, p. 86). Contudo, mesmo reconhecendo o caráter histórico das "diferenças percebidas" entre sexos, a perspectiva de Scott aqui apresentada pode ser interpretada como atribuindo uma existência "natural" ao sexo como anterior ao gênero, sendo este entendido como cultural e historicamente definido sobre diferenças preexistentes - sejam elas percebidas ou não -, sem considerar tanto a construção e a reiteração dessas diferenças.

Sob outro ângulo, Judith Butler questiona mais incisivamente a ideia de gênero como significação cultural de diferenças essenciais entre os sexos, a qual parte da perspectiva de existência de um sexo - masculino ou feminino - anterior à cultura e, portanto, "natural". Conforme a autora:

O gênero não deve ser meramente concebido como a inscrição cultural de significado num sexo previamente dado [...]; tem de designar também o aparato mesmo de produção mediante o qual os próprios sexos são estabelecidos. Resulta daí que o gênero não está para a cultura como o sexo para a natureza; ele também é o meio discursivo/cultural pelo qual "a natureza sexuada" ou "um sexo natural" é produzido e estabelecido como "pré-discursivo" [...] (Butler, 2013, p. 25).

Desse modo, Butler adentra na discussão sobre a sexualidade e seus aspectos discursivos na constituição de gênero, problematizando a ideia de identidades coerentes de gênero inteligíveis, pautadas por uma continuidade fixa entre sexo, gênero e desejo:

Gêneros “inteligíveis" são aqueles que, em certo sentido, instituem e mantêm relações de coerência e de continuidade entre sexo, gênero, prática sexual e desejo. Em outras palavras, os espectros de descontinuidade e incoerência, eles próprios só concebíveis em relação a normas existentes de continuidade e coerência, são constantemente proibidos e produzidos pelas próprias leis que buscam estabelecer linhas causais ou expressivas de ligação entre o sexo biológico, o gênero culturalmente constituído e a "expressão" ou "efeito" de ambos na manifestação do desejo sexual por meio da prática sexual (Idem, p. 38).

A problematização do desejo sexual como norma naturalizada contribui para complexificar os debates de gênero quando essa ilusão de coerência e continuidade 
é colocada à prova e se percebe que ela é constantemente reiterada por discursos e práticas em diferentes esferas - da jurídica à íntima e afetiva. Colocam-se em questão mesmo aqueles comportamentos, sentimentos e sensações mais naturalizados, no que a atração sexual - expressão mais direta de uma pulsão fisiológica para o senso comum - assume um aspecto socialmente constituído. Isso não nega a existência de pulsões, bem como não contradiz a materialidade dos corpos e seus impulsos. Práticas coerentes - no que se incluem até mesmo formas de pensar e sentir - são estimuladas conforme gêneros atribuídos desde o nascimento. Partindo então da perspectiva de que os corpos são disciplinados (Foucault, 2009), pode-se interpretar que a significação dos sentimentos e os prazeres também operam conforme regimes disciplinares, sendo alguns considerados "nobres” e, portanto, incentivados, como é o caso do amor romântico - heterossexual e monogâmico -, ou "abomináveis", como são referidos todos os comportamentos que fugiriam a essa matriz.

Não só os indivíduos aprendem a agir, apresentar-se e reconhecer-se conforme gêneros atribuídos, mas também esse processo se dá de forma ativa, como práticas e discursos que reiteram - para si e para os outros - noções de identidades coerentes. Destarte, outra contribuição fundamental de Butler reside na noção de performatividade, que, segundo a autora, “deve ser compreendida não como um 'ato' singular ou deliberado, mas, ao invés disso, como a prática reiterativa e citacional pela qual o discurso produz os efeitos que ele nomeia” (Butler, 2000, p. 111). Mais adiante, ela complementa:

A performatividade não é, assim, um "ato" singular, pois ela é sempre uma reiteração de uma norma ou conjunto de normas. E na medida em que ela adquire o status de ato no presente, ela oculta ou dissimula as convenções das quais ela é uma repetição. Além disso, esse ato não é primariamente teatral; de fato, sua aparente teatralidade é produzida na medida em que sua historicidade permanece dissimulada (Idem, p. 121).

Reconhecendo as contribuições de Butler e Scott, parte-se aqui de dois axiomas: (1) as noções de gênero possuem uma historicidade enquanto formas de significação de diferenças e relações de poder, sendo, portanto, variáveis e cambiantes; e (2) não sendo uma propriedade fixa dos corpos, mas um agir constante que se reitera através de práticas e discursos que demandam reconhecimento, o gênero é constantemente produzido e negociado no campo das relações sociais, implicando aprendizados, tanto no nível prático performativo como no nível discursivo enquanto autojustificação. Assim, nota-se uma indissociável relação entre uma compreensão sociológica de gênero e socialização, sendo esta percebida como contínua e não limitada às instituições familiar e escolar. 
Isso suscita várias questões: como e por quais meios suas práticas são aprendidas, especialmente as que dizem respeito à subjetividade, às emoções e às relações íntimas? Como esses aprendizados se legitimam e se estendem para um sem número de indivíduos que os reconhecem, reproduzem e, eventualmente, ensinam ao mesmo tempo que acreditam "viver naturalmente" em coerência com seus desejos e sua individualidade? É neste ponto que a questão das imagens produzidas e difundidas por aparatos tecnológicos de audiovisual e mídias digitais revela-se importante: sobretudo naquilo que, atualmente, nos parece mais familiar e corriqueiro, tantas vezes visto, reconhecido e às vezes retransmitido como autoevidente.

\section{O feminino em imagens}

Desde os anos de 1980, têm-se visto muitos trabalhos acerca das “representações" do gênero feminino em imagens, com especial destaque para o cinema de grande público e imagens publicitárias em mídias impressas (Passerini, 1991; Lauretis, 1994; Louro, 2008; Beleli, 2010). Em sua maioria, é feita alguma articulação direta com a temática do consumo, sendo recorrente o tema da objetificação das mulheres, no que ocorreria uma forte alusão do corpo feminino a um potencial de aquisição e consumo: "a hegemonia da figura feminina na publicidade, nas capas das revistas e nos cartazes remete com efeito para a coincidência entre a mulher como potencial sujeito e a mulher como possível objeto" (Passerini, 1991, p. 382). Essa objetificação não se restringe ao corpo feminino disposto nas imagens; este materializa, visualmente, sentimentos e estados de espírito a princípio ininteligíveis como prazer, desejo, felicidade, sucesso e conquista, que, amiúde, ganham caráter erotizado.

Havendo-se constituído social e historicamente uma percepção que associa diretamente emoções à feminilidade, em muitos casos o uso publicitário de imagens de mulheres remetem a esses elementos, que se tornam "visíveis" pelos contornos bem definidos de um corpo feminino. A mulher é tomada então, em contraponto à "realidade objetiva" masculinizada, como a imagem do desejo, da fragilidade, do descontrole, do arrebatamento. Entretanto, mesmo em sua exaltação, esse contraponto, em uma escala valorativa moderna, é rebaixado por remeter a tudo que, a princípio, seria nocivo ao projeto racionalista e pragmático da modernidade, "justificando", por sua vez, sua assimilação, controle e instrumentalização de forma "produtiva".

Outro elemento muito presente na literatura relacionada com gênero e imagens, tanto na pesquisa como na militância, é o discurso da visibilidade:

Tornar visível aquela que fora ocultada foi o grande objetivo das estudiosas feministas desses primeiros tempos. A segregação social e política a que as mulheres foram historicamente 
conduzidas tivera como consequência a sua ampla invisibilidade como sujeito - inclusive como sujeito da Ciência (Louro, 1997, p. 17).

Ao realizar a busca por vídeos circulantes na internet e nas redes sociais relacionados com as temáticas de gênero e sexualidades, notou-se a recorrência de anúncios de campanhas, eventos, textos e datas comemorativas utilizando-se do termo visibilidade 3 . O clamor por visibilidade, no sentido político, torna-se cada vez mais frequente entre diversas matrizes de movimentos feministas e LGBT, que problematizam tal visibilidade em produtos audiovisuais - novelas, filmes, comerciais - e incentivam produções, muitas vezes consideradas “independentes”, que promovam o protagonismo de personagens invisibilizados.

Para além de seu sentido metafórico e político, como sugere Louro (1997) didaticamente partindo de referências desde o movimento sufragista, o tema da visibilidade também é explorado em sua literalidade, focando na produção de imagens do feminino em diferentes meios de comunicação. Se, por um lado, a imagem do feminino associada à vida privada do lar é preservada na invisibilidade sob o pretexto de uma atitude "reservada", por outro, o uso de imagens do corpo feminino em meios de comunicação, uma vez objetificado, tornar-se-ia desprovido desse aspecto de "privacidade" para significar, de forma ampla, e corporificada, o desejo em si, sob uma matriz heterossexualizada e masculinista de orientação desse desejo. Desse modo, visualizados tantas vezes como signo universal do desejo e de pulsões emocionais e sexuais, corpos femininos são superexpostos, o que confere ao feminino visibilidade como objeto, mas, raramente, como sujeito.

Um trabalho que se tornou referência em questões de gênero e imagens é o de Teresa de Lauretis, ao problematizar o cinema como uma entre outras "tecnologias de gênero [...] com o poder de controlar o campo do significado social e assim produzir, promover e 'implantar' representações de gênero" (Lauretis, 1994, p. 228). Evidencia-se no trabalho de Lauretis, como em outros estudos, o problema da [in] visibilidade de grupos, práticas, sexualidades e discursos colocados à margem dos discursos hegemônicos, continuamente reproduzidos e reiterados em meios de comunicação de massa. O uso recorrente do termo visibilidade, de expressões como outros olhares ou propostas de problematizar "a 'naturalização' dos modos como as pessoas se veem e são vistas” (Beleli, 2010, p. 46) são particularmente significativos nos textos políticos e acadêmicos que tratam de gênero.

3. Dia Nacional da Visibilidade Lésbica (29 de agosto); Dia Nacional da Visibilidade Trans (29 de janeiro); a comunidade "Mulheres Negras Construindo Visibilidade", entre outros. 
A visibilidade só se torna questão de debate científico ou político em sociedades que lhe atribuem um estatuto especial de reiterar, produzir ou ocultar verdades, o que confere aos estudos a esse respeito um prisma que extrapola as abordagens fundamentadas na dicotomia representação/realidade. Nesse sentido, os aparatos fotográfico e cinematográfico têm especial valor pela suposta neutralidade e precisão que lhes são atribuídas. Mesmo quando se trata de imagens fictícias, elas tendem, nessa cultura, a ser lidas na chave do seu grau de parecença com noções de "realidade" também constituídas socialmente e, não raramente, através da relação com outras imagens, mais que com experiências em si.

Percebe-se em muitos discursos a crítica de que as "representações" do feminino nos meios de comunicação audiovisual, na publicidade e na mídia impressa não corresponderiam à "realidade" ao priorizar imagens de modelos conforme padrões estéticos eurocêntricos bem definidos: magras, altas, brancas e jovens. Aparentemente, com a expansão do acesso a tecnologias de produção e reprodução de vídeos - das câmeras portáteis e projetores caseiros ao videocassete; de aparelhos celulares com câmera a tablets com acesso a vídeos hospedados na internet -, esse movimento de contraposição entre "realidade" e "representação" pareceu se intensificar com a possibilidade de, através de redes sociais e aparatos de baixo custo, pessoas compartilharem "diretamente" seus vídeos e visões de "realidade". De todo modo, há ainda um clamor por "imagens mais realistas" do feminino, elemento do qual a publicidade já se apropriou há algum tempo, como se pode observar nos comerciais dos produtos de higiene e cosmética da marca Dove, com sua campanha de "Beleza Real", da qual participam mulheres gordas e magras, altas e baixas, de diferentes etnias e faixas etárias, constituindo com isso uma outra imagem do "real", marcada pelo contraponto às imagens de modelos profissionais.

Ao mesmo tempo que se dedica cada vez mais energia em debates que problematizam o "realismo" e "realidade" das imagens, o que se percebe, ironicamente, é que essa discussão se dá justamente em um contexto em que o entendimento do "real" se pauta, sobretudo, por sua visibilidade enquanto passível de ser mecanicamente registrado, constituindo uma relação de quase independência do objeto registrado. As imagens se tornam separadas e, muitas vezes, independentes do contexto de sua produção, embora, constantemente, sejam [re]contextualizadas para que façam sentido e tenham seu estatuto de "realidade" reconhecido. Com isso, elucida-se o quanto é problemática a clivagem entre "realidade" e "representação", sendo o último termo frequentemente utilizado como correspondente à "imagem".

Concorda-se aqui com a afirmação de que a "publicidade não inventa coisas, seu discurso, suas representações, estão sempre relacionadas com o conhecimento que circula na sociedade; suas imagens trazem sempre signos, significantes e significados 
que nos são familiares" (Sabat, 2013, p. 150). Portanto, as análises sociológicas, tanto fílmicas como fotográficas, não deveriam buscar a realidade ou a materialidade do mundo, do qual as imagens seriam supostamente mero reflexo ou representação mais ou menos ideológica. De forma mais profunda, elas consistem em análises de relações de sentido que, a um só tempo as transcendem e apropriam-se delas para se manterem e, assim, instigarem indivíduos a se vestir, andar, portar e, até mesmo, sentir prazer - independentemente de suas possibilidades de aquisição dos produtos anunciados - e, portanto, a agir e interagir socialmente.

Precisamente naquelas imagens que são "entendidas" de forma mais irrefletida e pretensamente "imediata” que residiria o cerne da análise sociológica de imagens. A impressão de autoevidência só é possível onde os signos e os significados são tão reconhecidos e familiares que seu aspecto interpretativo passa despercebido, uma vez que é cotidianamente reiterado desde os primeiros anos de vida. Isso demanda, portanto, um profundo estranhamento da própria percepção, afinal, conforme Goffman (1987, p. 13), a facilidade com que um indivíduo apreende o significado de uma fotografia publicitária advém precisamente de sua tendência a evitar a necessidade de pensar a respeito. Portanto, pensar imagens que foram calculadamente produzidas para não serem pensadas, fundamentando-se em conhecimentos, signos e pré-noções naturalizados conduz a um questionamento menos das imagens em si que das formas com que se aprende a olhá-las e, concomitantemente, a olhar a própria realidade.

Lauretis já sugerira que "gênero é representação - o que não significa que não tenha implicações concretas ou reais, tanto sociais quanto subjetivas. Muito pelo contrário, [...] a representação de gênero é sua construção" (Lauretis, 1994, p. 208). Contudo, em seu argumento, ao enfatizar os aspectos ideológicos das representações de gênero na mídia cinematográfica e no que ela "deixa de mostrar", parece haver a insistência na contraposição entre "realidade" e "representação". Além de problemático para a análise de imagens, na medida em que se nota uma demanda por "representações mais realistas", o termo representação ainda se mostra polissêmico, mas sua significação - de representação política a representação social e estética - não é, muitas vezes, mediada, como se em diferentes campos analíticos a palavra assumisse o mesmo sentido e o mesmo peso.

Um debate no campo das imagens sobre o suposto realismo esperado ou reivindicado das representações por si só já expressa uma característica culturalmente distinta das sociedades modernas, marcadas sobretudo pela consagração dos aparatos fotográfico e cinematográfico, aos quais é conferido um estatuto especial de captar, mecânica e objetivamente, qualquer "realidade" que se apresenta dentro de seu espaço de enquadramento. Menezes já chamara atenção para o fato de que "um filme não é uma representação do real, pois a representação não se confunde com o próprio real” 
(Menezes, 2004, p. 90). A representação não necessitaria atender a um estatuto de semelhança com o objeto representado, mas operar justamente conforme uma reconhecida alusão. Contrapor, portanto, "realidade” e sua "representação" em imagens tomando por base a fidedignidade da última à primeira seria então um erro primário. A questão, então, se desloca do que é ou não representado pelas imagens para o que aprendemos a reivindicar e constituir como "real" com base em e, principalmente, através de imagens. O que aparenta ser uma contraposição entre "imagem e realidade" revela-se uma contraposição entre imagens - todas elas construídas, mediadas, selecionadas e editadas - conflitando por legitimidade e reconhecimento, em lutas simbólicas onde o real e o imaginário são indissociáveis e se constituem mutuamente de forma pouco fidedigna ou consensual.

Nota-se então, no antagonismo entre "representação" e "realidade", um falso problema ou, no mínimo, um descentramento das questões mais relevantes para o debate. Trata-se aqui menos de discutir gradações de realidade ou a suposta função ideológica das imagens de ocultá-la para reproduzir mecanismos de opressão. Mais precisamente, é em um contexto social específico - em que essas imagens captadas mecanicamente e difundidas em larga escala adquirem particular relevância para definir e reconhecer "o que é real" - que a discussão se direciona para a própria construção de sentidos, valores e discursos que orientam ações e interações na vida cotidiana, constituindo assim, de uma perspectiva sociológica, convenções do que é partilhado como "realidade".

A luta de grupos que clamam por mais visibilidade é importante não por revelar uma realidade "oculta", mas, precisamente, por fazer parte reconhecida da constituição da realidade. E essa relação entre imagens e realidade se complexifica ainda mais com a difusão das mídias digitais e a possibilidade de constituir formas outras de produção e reprodução de imagens e vídeos, cada vez mais independentes de veículos especializados de comunicação, como emissoras de TV, estúdios de cinema e distribuidores. Sob tal aspecto, as possibilidades de difusão de imagens produzidas de maneira autônoma, muitas vezes caseiras, bem como a participação de usuários $\mathrm{da}$ internet e das redes sociais nas campanhas publicitárias promovem novas relações de aparente aproximação com a "realidade" pela intensificação do uso de tecnologias de imagem que se apoiam cada vez menos em um entendimento de realidade a partir do presencial e do concreto.

Imagens e "realidades" nas mídias digitais

O presente contexto de difusão das mídias digitais e acesso à internet bem como a rápida expansão de tecnologias de telecomunicações desde os anos de 1990 até hoje 
oferecem uma série de desafios para a análise sociológica. Muitas vezes, o ritmo da pesquisa parece não acompanhar o das mudanças observadas, especialmente quando se consideram diferenças geracionais relevantes na percepção desses fenômenos entre aqueles que cresceram e se formaram já inseridos nesse contexto e as gerações que se formaram antes desse fenômeno:

O uso da rede é muito maior entre aqueles que nasceram ou chegaram à adolescência em meio à sua expansão comercial no final da década de 1990, portanto tendo mais chance e interesse de acionar seu uso para manter e/ou expandir suas relações sociais. Pessoas nascidas antes da década de 1970 já eram adultos com mais de 25 anos em 1997, portanto já haviam sido educados, socializados e constituído boa parte de seus vínculos sociais por outros meios (Miskolci, 2011, p. 10).

Há que se considerar que, para as gerações socializadas desde a infância com acesso à internet como parte de suas interações cotidianas, essa relação com as imagens é radicalmente diferente, assim como seria o caso das gerações marcadas pela popularização da televisão em comparação às precedentes. Em relação a isso, Lahire (2006, p. 516) já apontara, em meados dos anos 2000, que "adolescentes e pós-adolescentes cresceram em um novo estado de oferta cultural (comparado àqueles que viveram sua adolescência nos anos de 1960), caracterizado particularmente por uma forte presença das mídias audiovisuais".

Quando se levam em conta as gerações nascidas a partir dos anos de 1990, pensar o "mundo real" em oposição ao "mundo virtual" ou ao mundo das imagens revela-se um binarismo retrógrado. As diversas possibilidades de interação, acesso a serviços, construção de identidades e de relacionamentos afetivos proporcionadas pelas mídias digitais e pelos novos aparatos de comunicação constituem, por si, especialmente para essas gerações, experiências e situações reais. Conforme Scott McQuire (2008, pp. 203-204):

Argumentei que as mídias modernas não são simplesmente formas de "representação", no sentido de prover imagens que reflitam ou distorçam uma realidade social já estabelecida em qualquer lugar. Antes, sugeri que as novas plataformas de mídia têm contribuído de modo consistente para a formação de novos modos de percepção e conhecimento, bem como para a produção de novas formas e locais de ação social. [...] Mídias não mais pertencem primariamente a locais especializados espacialmente delimitados tais como o cinema, mas estão se tornando móveis e penetrantes. Mais do que registro de eventos passados, mídias digitais oferecem com frequência feedback instantâneo em "tempo real". Não somente as interações sociais rotineiramente distribuídas através de matrizes heterogêneas de tempo- 
-espaço, mas também a mediação por sistemas tecnológicos complexos tornou-se integral para a dinâmica social.

As imagens, bem como as possibilidades de visualização delas, revelam-se fundamentais para a experiência, sendo que as mídias digitais, em conjunto com as novas possibilidades de registro, manipulação e compartilhamento das imagens por atores não especializados, abrem campo para uma série de questões, entre as quais a constituição da própria subjetividade como apresentação de si, tanto pelo registro e compartilhamento das próprias imagens, quanto por alusão e recurso a outras imagens do cinema, da publicidade e da televisão. Estas também, muitas vezes manipuladas amadoristicamente com legendas, redublagens e outros recursos, são, assim, ressignificadas.

Entende-se que os usos dessas novas mídias, tanto para gravar como para compartilhar vídeos, sejam eles íntimos ou não, publicitários ou educativos, possuem um aspecto de performatividade, nos termos de Butler, enquanto práticas reiterativas e citacionais de determinadas noções de identidade. Embora se reconheçam nessas práticas, especialmente diante das câmeras, aspectos teatralizados, há, em grande medida, um esforço em negar qualquer teatralidade e afirmar para si e para os demais interlocutores a autenticidade de sua própria performance. Goffman (1987, p. 7) já pontuara que "somos socializados para confirmar nossas próprias hipóteses sobre nossas naturezas". Desse modo, o compartilhamento de conteúdos e imagens em redes sociais é uma forma de reiterar posicionamentos e noções de identidade, buscando também respaldo em signos reconhecidos de acordo com sua difusão por meios de comunicação de massa. Cabe então refletir sobre como a performatividade de gêneros é trazida para as novas formas de interação promovidas pelas mídias digitais, ressaltando, nesse caso, sua relação com recurso a imagens e vídeos. Assim, a performatividade se estende às interações não presenciais, ao recurso a imagens de si ou alusões aos próprios sentimentos por imagens de outrem, assumindo um aspecto mediado pelos próprios usuários, não em oposição à sua "realidade" entendida no sentido mais concreto, mas de forma ativa e integrante desta realidade, constituída por incontáveis ficções e alusões.

Boa parte da comunicação visual corrente nas mídias digitais apoia-se no uso de imagens e referências televisivas e cinematográficas que, não raramente, resgatam produções anteriores ao nascimento da maioria dos usuários. De fotogramas de personagens consagrados como Holly Golightly (Audrey Hepburn em Breakfast at Tiffany's, 1961) a Rocky Balboa (Sylvester Stallone em Rocky, 1976 e demais sequências), com legendas criadas pelos internautas às vezes com propósitos cômicos ou, em outros casos, utilizadas em defesa de posicionamentos morais ou para a 
comunicação de estados emocionais, nota-se que a comunicação aqui empregada não é sem precedentes nem avessa a produções anteriores. Ao contrário, ela se apropria destas abertamente, ressignifica-as e as reaviva ao recontextualizá-las como recurso expressivo de gostos, crenças, valores e da própria subjetividade. Sublinha-se então que "alguém interessado em explorar o estudo de mídias digitais precisa estar atento para o fato de que elas potencializam e transformam meios anteriores de comunicação, os quais, por sua vez, já foram inovadores e causaram grandes mudanças sociais e subjetivas" (Miskolci, 2011, p. 10).

Isso posto, observou-se no processo de busca por vídeos publicitários na rede social Facebook que a maior parte do material não é compartilhada pelos usuários no sentido de promover a venda deste ou daquele produto. Frequentemente, um vídeo publicitário aparece na rede social como objeto - central ou acessório - de crítica e debate, como foi o caso da campanha Juntas contra Vazamentos (2015), da marca de absorventes Always em parceria com a ONG SaferNet. A campanha foi introduzida com um suposto vídeo privado da apresentadora Sabrina Satto que teria vazado e viralizado ${ }^{4}$ na internet. Após a difusão desse conteúdo, a marca revelou sua campanha, fazendo uma analogia pitoresca entre o vazamento de vídeos íntimos e o vazamento de sangue menstrual.

Em associação com uma ONG que visa a promover a segurança na circulação de informação e conteúdos na internet, a campanha lançou-se também com certo viés "educativo" no sentido de prevenir mulheres contra o compartilhamento não consentido de vídeos íntimos por iniciativa de parceiros ou ex-parceiros. O principal canal de difusão desses vídeos geralmente é o aplicativo para celulares de mensagens instantâneas no Whatsapp, através do qual é possível participar de diferentes grupos de usuários, em que conteúdos diversos são rapidamente compartilhados e visualizados.

A campanha foi bastante criticada em diferentes páginas da internet, tanto pela duvidosa analogia entre o vazamento de sangue menstrual e o vazamento de vídeos íntimos, quanto pelo uso da imagem da apresentadora, o que reforçaria o aspecto de erotização do corpo feminino:

Na campanha, acharam que seria uma boa ideia falar sobre vídeos íntimos que são publicados sem o consentimento das mulheres gravadas, mas resolveram abordar o tema criando um viral porco, utilizando a famosa Sabrina Sato como exibição sexualmente objetificada,

4. Expressão que se refere a conteúdos que se espalham rapidamente nas redes sociais com o compartilhamento dos próprios usuários. Muitas vezes, o conteúdo apresenta uma notícia ou vazamento de informação falsa, sem remeter à marca que a promove. A "revelação" de que se trata de uma campanha publicitária - e de seus objetivos - se dá posteriormente, após a difusão do conteúdo e a instauração de alguma polêmica ou discussão a respeito. 
apresentando um assunto extremamente difícil com trocadilhos ridículos e irresponsabilidade profunda (Arraes, 2015).

Criticou-se também a responsabilização das vítimas pelo vazamento desses vídeos, que geralmente acontece por iniciativa de parceiros ou ex-parceiros: "O site da marca dá dicas para que as mulheres se protejam da divulgação das fotos indesejadas na internet, mas a culpa disso não é de quem espalha esse material sem autorização?" (Morais, 2015). É importante observar aqui esse movimento de difusão muito específico da publicidade na internet, que se apoia, mais do que em outros veículos, na participação dos usuários.

A difusão de uma campanha pode ocorrer tanto pela crítica como pela aprovação dos usuários. Nesse sentido, a jornalista Rebeca de Morais aponta uma crescente preferência de consumidores usuários das redes sociais por marcas que expressem posicionamentos políticos em relação a diferentes causas e movimentos. Outro exemplo nesse sentido foi a campanha de Dia dos Namorados da marca O Boticário em 2015, que circulou na internet e na televisão, na qual as imagens sugerem a celebração do Dia dos Namorados entre parceiros homoafetivos. Assim, muitas vezes, um comercial é compartilhado nas redes sociais como expressão de posicionamentos morais em relação a diferentes assuntos. E se, por um lado, a visibilidade atingida por mulheres e outros grupos considerados minorias talvez não seja ainda tão expressiva nos vídeos publicitários em si, por outro, os debates promovidos por representantes desses grupos nas redes sociais sobre a recepção das campanhas, especialmente quando reforçados por textos e blogs de colunistas e sites de notícias renomados, contribuem para uma visibilidade um pouco maior das pautas desses grupos. Seus posicionamentos podem ter tanto um sentido político, inseridos em debates mais amplos como o combate ao racismo, à homofobia, à violência contra a mulher, como podem ter um sentido afetivo, expressando posições valorativas e de gosto, como é o caso de empresas que lançaram campanhas com "homenagens surpresas" como a marca de cosméticos Natura, em 2011, em parceria com o site www.ingresso.com, ou a campanha Histórias Reais do Primeiro Encontro, da linha de lavadoras de roupas da marca Samsung (2014).

Nos diferentes vídeos analisados, é notável o apelo para a "realidade", algumas vezes com participação direta de usuários da marca e contribuição de parceiros e amigos, como é o caso do referido comercial de lavadora. $\mathrm{O}$ vídeo começa com entrevistas intercaladas de três mulheres de diferentes gerações falando sobre como seus parceiros se lembram de datas, detalhes e momentos especiais vividos pelo casal. A primeira parte acaba com o comentário de uma delas aludindo ao lugar comum de que homens em geral não têm esse tipo de memória. Corte, sobre uma tela azul lê-se a seguinte frase: “Será mesmo?” A partir daí, todo o vídeo se estrutura de modo 
a conduzir à grande surpresa. Cenas dos companheiros escrevendo uma carta e procurando roupas em um armário são intercaladas às imagens das câmeras escondidas que mostram as mulheres chegando em casa. Ao abrirem a porta, deparam-se bem no meio da sala com uma lavadora de roupas envolta a um grande laço de presente. Emocionadas e sem saber ao certo o que está acontecendo, lêm a carta do parceiro que, no final, contém instruções a serem seguidas. Deveriam vestir a roupa usada no primeiro encontro, que eles haviam colocado no interior da lavadora, e sair; à sua espera, uma limosine estacionada em frente da casa as conduz justamente para o local do primeiro encontro, onde seus companheiros as aguardam. Novo corte, nova tela azul, e o desfecho "triunfal" que sugere a importância que uma simples peça de roupa pode ter na memória afetiva de um casal, fazendo aí o gancho para o produto que se quer vender: a máquina de lavar.

Conservar objetos, no caso aqui a roupa, como o comercial insinua, é uma maneira de resguardar memórias afetivas, e para tanto nada melhor do que ter bons produtos que possam garantir isso. Mas, indo além, o comercial se estrutura sobre uma construção binária de diferenciações estereotipadas de gênero: mesmo para a entrevistada que diz, de maneira jocosa, que é seu companheiro quem lembra das datas etc., o tom é de que se trata de algo inusitado, corrobarando, então, para o senso comum de que homens não se preocupam com esse tipo de coisa. A grande "surpresa" aludida no comercial refere-se, pois, à capacidade deles de, em sinal de afeto, preservarem e resgatarem, com riqueza de detalhes e por longo período de tempo, lembranças do início de seu relacionamento amoroso.

Em outra campanha com características semelhantes, três lojas de roupas e acessórios femininos de São Luís, no Maranhão, juntaram-se para fazer algo inusitado: partindo de um discurso do senso comum de que homens não notam mudanças no visual de suas parceiras, a campanha promoveu, valendo-se também de câmeras escondidas, um encontro entre casais selecionados em um restaurante. As mulheres se retiravam para ir ao toalete e, nesse momento, recebiam um tratamento de beleza completo, com roupas, acessórios e maquiagem das grifes que promoviam a campanha. Aqui o contraponto é ainda mais exagerado e pouco convincente, pois os homens ficam embasbacados quando suas esposas aparecem quase irreconhecíveis sob um novo penteado, maquiagem e um vestido de noite completamente diferente dos trajes com que chegaram ao restaurante, o que, portanto, provaria que eles talvez não fossem tão desatentos assim. O comercial não só contribui para uma imagem idiotizada dos parceiros, que obviamente percebem e se surpreendem com a transformação das mulheres, mas também reitera o aspecto de objetificação do corpo feminino, notado primordialmente por seu "valor" estético. As declarações de amor dos homens por suas parceiras registradas em forma de entrevista ao final do vídeo reforçam, de forma 
constrangedoramente naturalizada, o peso da relação inculcada sobre o feminino, em que a produção estética da aparência se revela como requisito primordial para o usufruto do direito de ser amada (por um homem).

Depois da recente expansão de acesso e utilização de mídias digitais, as queixas, ainda que presentes, incidiram cada vez menos sobre a aparência supostamente distante da "realidade" da modelo ou atriz profissional que estrela as campanhas publicitárias em relação às potenciais consumidoras do produto anunciado. Embora seja evidente que os produtos estão restritos a certo nível de poder aquisitivo e são acessíveis a apenas determinados capitais simbólicos, a aproximação com a consumidora nesse tipo de campanha decorre do pressuposto de que não se trata de atores ou modelos encenando o uso dos produtos, mas pessoas aparentemente "comuns".

Entre surpresas e elogios, são frequentes nesses vídeos depoimentos de participantes, simulando entrevistas, que remetem a filmes documentários. No caso da campanha da Always e SaferNet, também são incorporados depoimentos de mulheres que teriam sido vítimas do vazamento na internet de vídeos íntimos. Pode-se citar também a campanha do Dia dos Namorados de O Boticário de 2014, em que a marca incentivava seus usuários a enviarem vídeos de homenagem a seus parceiros para compartilharem no site da empresa. E durante a campanha, foi feita uma montagem intercalando cenas de vários desses vídeos. A proposta é apresentada na abertura com a seguinte legenda: "Prepare-se para ver momentos de tirar o fôlego com histórias reais". Há um apelo distintamente "cinematográfico" nos registros desses usuários e que parece reforçado pela trilha sonora empolgante da campanha no mosaico montado de cenas pinçadas de seus espetáculos "particulares”, também encenados e calculados perante as câmeras, mas apresentados como "histórias reais" pelo registro e compartilhamento espontâneo dos participantes da campanha.

Em relação às estratégias publicitárias de identificação com o potencial público consumidor, Beleli observa que

\footnotetext{
Nessa mediação, a evocação da "experiência", como sinônimo de autenticidade, é uma importante estratégia publicitária para despertar a atenção do consumidor, propondo identificações entre as vidas cotidianas e aquilo que as marcas/produtos oferecem. Nesse sentido, uma propaganda eficaz é aquela que oferece a "sensação" de que o consumidor está escolhendo livremente um modo de ser (2007, p. 194).
}

Aparentemente, as novas mídias potencializam essa evocação da experiência, não somente em função das possibilidades de feedback e participação dos consumidores enquanto usuários das redes sociais, mas, de forma mais incisiva, pela incorporação dos estereótipos pelos próprios consumidores. Seu comportamento “real”, suas rea- 
ções às surpresas, o conteúdo das homenagens, bem como a produção de seus vídeos "realistas", ao mesmo tempo que reiteram estereótipos de gênero já arraigados nas relações sociais cotidianas - e pela exposição a filmes, televisão e a diferentes formas de publicidade - constituem parâmetros de "realidade" também estereotipados. Das narrativas dos comerciais que intercalam trechos de entrevistas à estética aparentemente rústica das imagens de câmeras escondidas - que limitaria bastante as possibilidades de controle e interferência na iluminação ambiente -, passando pela utilização de aparatos de gravação de vídeo dos próprios participantes, tais como as câmeras embutidas em seus computadores pessoais ou telefones celulares, tem-se uma série de elementos de percepção socialmente compartilhados para definir hoje uma campanha publicitária nas novas mídias como mais “realista”. Isso inclui, necessariamente, ao fim de cada vídeo, a divulgação de canais que possibilitem aos usuários que visualizam os vídeos expor publicamente seus comentários e impressões sobre eles e, caso lhes interesse, divulgá-los em diferentes redes sociais.

Considerando que a maior parte das campanhas publicitárias aqui analisadas, guardadas as devidas especificidades, são filmes em seu aspecto de construção, vale salientar que:

Um filme não é nem uma História e nem uma duplicação do real fixada em celulose: é uma mise en scène social e isto por duas razões. O filme constitui primeiramente uma seleção (certos objetos e não outros) e depois uma redistribuição. Ele reorganiza, com elementos tomados essencialmente dentro do universo ambiente, um conjunto social que, em certos aspectos, evoca o meio de onde ele é içado, mas, essencialmente, é uma retradução imaginária (Sorlin, 1982, p. 200).

As "histórias reais" aqui referidas, nesse sentido, são também uma mise en scène social, encenada por seus participantes. Há também que se observar que os códigos empregados nesses vídeos publicitários - da trilha sonora ao ritmo da narrativa visando a um climax - guardam referências a todo um imaginário de filmes hollywoodianos e telenovelas, enquanto, muitas vezes, o estatuto de "realidade" é atribuído à qualidade da gravação, captada por microcâmeras ou câmeras de celular. Os códigos de sensibilização aqui empregados e reiterados são então muito menos reflexo de uma pressuposta materialidade do "mundo real" do que resultado de relações de sentido estabelecidas entre imagens, absorvidas e naturalizadas na vida cotidiana.

A penetração no cotidiano de aparelhos de telefonia celular com câmera e recursos de compartilhamento imediato de vídeos e imagens através de Facebook, Instagram ${ }^{5}$

5. Rede social especificamente voltada para compartilhamento de imagens. 
e Whatsapp constitui uma relação com as experiências por meio da sua presentificação via seu compartilhamento imediato. Hábitos correntes em redes sociais, como divulgar fotos de refeiçao, poses em academia de ginástica etc., expressam uma dupla relação de mediação entre imagens e experiência: a experiência, ao mesmo tempo, é mediada por imagens, como o próprio ato de mediá-las se torna parte e, muitas vezes, o próprio cerne da experiência, afinal seu registro só ganha sentido pela possibilidade de publicização, ainda que para um grupo restrito de amigos e conhecidos nas redes sociais.

\section{Considerações finais}

Partindo de uma breve revisão teórico-metodológica articulada a resultados parciais da análise dos vídeos da pesquisa, buscou-se aqui uma reflexão mais crítica e aprofundada das complexas relações entre imagens publicitárias, feminilidade e as diferentes mídias mobilizadas em sua [re]produção. A questão da naturalização mostrou-se central para além do debate de elementos atribuídos a gêneros na qualidade de "sexo", deslocando-se para a naturalização de percepções da própria realidade centralizadas na visualidade e profundamente afetadas pela rotinização do uso de novas mídias e tecnologias na vida cotidiana. Nesse sentido, as noções de "representação" em oposição a uma suposta realidade preexistente revelaram-se defasadas, de modo que se defendem aqui abordagens que priorizem noções de construção social da realidade em que as relações com imagens e mídias digitais tenham sua importância e especificidade reconhecidas.

Em síntese, a proposta deste artigo foi, primeiramente, construir uma análise a partir da categoria gênero, tendo em vista seu caráter social, cultural e histórico e seus aspectos performativos, que implicam um agir constante, em grande medida consciente e que requer toda uma socialização e práticas reiterativas para sua fixação e reconhecimento, reforçando seu aspecto naturalizado. Em segundo lugar, problematizou-se a relação entre gênero, imagem e representação, propondo a desconstrução da noção de representação em oposição à "realidade" e enfatizando, especialmente no contexto hodierno, a importância das imagens e do sentido da visibilidade nos processos de socialização e constituição da realidade, incluindo-se aí noções inteligíveis de gênero. Nesse sentido, questionou-se a relação dicotômica muitas vezes assumida entre "realidade" e "representação", a qual frequentemente se desdobra na dicotomia entre sexo, concebido como "realidade objetiva”, e gênero, como "representação" culturalizada dessa realidade. Por último, ao suscitar as especificidades das mídias digitais, buscou-se problematizar relações de ressignificação de imagens que se constituem através dessas mídias e suas distinções em termos de 
produção e circulação em relação àquelas produzidas por organizações e empresas do ramo de comunicações de massa.

Não se ignora aqui que o acesso a essas mídias não é universal e, do ponto de vista socioeconômico, pouco ou nada democrático, o que revela um desafio ainda maior para sua problematização sociológica. Contudo, justamente porque as mídias digitais, no senso comum, são frequentemente caracterizadas como espaço de livre expressão e possibilidade de difusão da diversidade e visibilidade de "outras realidades”, elas instigam questões sociológicas: que discursos e imagens de realidade estão em disputa aqui? Que capitais simbólicos estão em jogo nessa disputa? Que formas e estratégias de legitimidade são produzidas nesse meio interativo e heterogêneo? E mais especificamente na temática de gênero: que dinâmicas de produção de identidades, sexualidades e afetividades são mobilizadas nessas mídias?

Sem pretensão de apresentar uma resposta derradeira a essas questões, mas lançando luz sobre um caminho possível, a literatura mobilizada neste artigo, devidamente articulada ao tratamento analítico dispensado aos vídeos, aponta insistentemente para a noção de visibilidade como elemento relevante de constituição de "realidades" socialmente reconhecidas hoje. Tal constituição, por sua vez, ocorreria, notadamente, de forma mediada tanto por produtores como por usuários das novas mídias. Desse modo, suscita-se uma série de problemas analíticos a serem levados em conta por pesquisadores que queiram se debruçar sobre as relações entre gêneros e imagens hoje, quando as novas mídias se tornam um recurso cotidiano de compartilhamento de certas imagens - e não de outras - e de produção, reafirmação e manutenção de performances e identidades.

Aparentemente, cada vez mais, através das novas mídias, o papel de "espectador" dá lugar ao papel de usuário: sua atividade na recepção dos conteúdos extrapola a experiência subjetiva quando suas impressões são (re)elaboradas para sua publicização em redes sociais. A convocação pela campanha Juntas contra Vazamentos, da marca de absorventes Always e da ONG SaferNet, para que usuárias participassem tirando e compartilhando fotos de si com o símbolo da campanha, é um exemplo expressivo desse tipo de relação estimulada nas mídias digitais. Sob esse prisma, a noção de protagonismo, não tanto em seu sentido político, mas em seus aspectos mais individualizados e narcísicos, parece ser reforçada no imaginário de usuários e usuárias, embora sua noção romantizada de autenticidade pareça cada vez mais questionável sob enxurradas de referências cinematográficas, gestos, poses e discursos estereotipados. Assim, tem-se a impressão de que, cada vez mais, há necessidade de aparecer bem apresentado perante as câmeras, mesmo que não haja ninguém olhando. E para o feminino, há tanto tempo tratado como imagem-objeto, isso pode significar, de forma ainda mais contundente, a conquista do reconhecimento da própria 
existência por sua visibilidade, corroborada pelo registro, difusão e feedback de suas imagens nas mídias digitais.

\section{Referências Bibliográficas}

Arraes, Jarid. (2015), "A publicidade brasileira é ridícula”. Revista Fórum, "Questão de Gênero". Disponível em http://www.revistaforum.com.br/questaodegenero/2015/03/05/ publicidade-brasileira-e-ridicula/, consultado em 13/9/2015.

Beleli, Iara. (2010), "Gênero". In: Miskolci, Richard (org.). Marcas da diferença no ensino escolar. São Carlos, Edufscar.

. (2007), "Corpo e identidade na propaganda". Estudos Feministas, Florianópolis, 1 (15): 193-215.

Berger, Peter \& Luckmann, Thomas. (1983), A construção social da realidade. Petrópolis, Vozes.

Butler, Judith. (2013), Problemas de gênero. Rio de Janeiro, Civilização Brasileira. . (2000), “Corpos que pesam”. In: Louro, Guacira Lopes (org.). O corpo educado. Belo Horizonte, Autêntica.

Foucault, Michel. (2009), História da sexualidade. Vol. 1: A vontade de saber. Rio de Janeiro, Graal.

Goffman, Erving. (1987), Gender advertisement. Nova York, Harper \& Row.

Lahire, Bernard. (2006), A cultura dos indivíduos. São Paulo, Artmed.

Lauretis, Teresa. (1994), “Tecnologia do gênero”. In: Hollanda, Heloísa Buarque de (org.). Tendências e impasses: o feminismo como crítica da cultura. Rio de Janeiro, Rocco.

Louro, Guacira Lopes. (2000), "Pedagogias da sexualidade”. In: (org.). O corpo educado. Belo Horizonte, Autêntica. . (2008), "Cinema e sexualidade". Educação e Realidade, 1 (33): 81-98.

McQuire, Scott. (2008), The media city. Londres, Sage Publications.

Menezes, Paulo. (2004), "O cinema documental como representificação”. In: Novaes, Sylvia Caiuby (org.). Escrituras da imagem. São Paulo, Edusp.

Miskolci, Richard. (2011), "Novas conexões: notas teórico-metodológicas para pesquisas sobre o uso de mídias digitais". Cronos. R. Pós-Grad. Ci. Soc., 2 (12): 9-22.

Morais, Rebeca de. (2015), "Não adianta apenas se engajar. O discurso tem que ser verdadeiro". BrasilPost: The Huffington Post. Disponível em http://www.brasilpost.com.br/rebeca-de-moraes/campanha-aways_b_6817810.html, consultado em 11/9/2015.

Passerini, Luisa. (1991), “Mulheres, consumo e cultura de massas”. In: Perrot, Michele \& Duby, Georges. História das mulheres no Ocidente. Porto, Portugal, Afrontamento, vol. 4. SABAt, Ruth. (2013), "Gênero e sexualidade para consumo”. In: Louro, Guacira Lopes et al. (orgs.). Corpo, gênero e sexualidade. Petrópolis, Vozes. 
Scotт, Joan. (1990), "Gênero: uma categoria útil de análise histórica”. Educação e Realidade, Porto Alegre, 2 (16): 5-22.

Sorlin, Pierre. (1982), Sociologie du cinéma. Paris, Aubier Montaigne.

\section{Vídeos citados}

JuntasContraVazamentos. Always Brasil. Disponível em https://www.youtube.com/ watch?v=pkW3M3dmGvY. Publicado em 24/3/2015, consultado em 13/9/2015.

Dia dos Namorados - O Boticário. O Boticário. Disponível em https://www.youtube.com/ watch?v=p4b8BMnolDI. Publicado em 25/5/2015, consultado em 13/9/2015.

Histórias Reais do Primeiro Encontro. Samsung Brasil. Disponível em https://www.youtube. com/watch?v=xf4o1jVnyio. Publicado em 29/7/2014, consultado em 13/9/2015.

Homenagem Surpresa no Cinema. Natura Brasil. Disponível em https://www.youtube.com/ watch?v=xjICQywTMQ4. Publicado em 27/10/2011, consultado em 13/9/2015.

O Boticário - Homenagem Dia dos Namorados. O Boticário. Disponível em https://www.youtube.com/watch?v=PLVz3oVzXxE. Publicado em 25/5/2014, consultado em 13/9/2015.

Toda Mulher Merece um Elogio. Lojas Villa, Scala, Carmen Steffens - São Luís, MA. Disponível em https://www.youtube.com/watch?v=GYyxcijttrY. Publicado em 7/3/2013, consultado em 13/9/2015. 


\section{Resumo}

Feminilidade e suas imagens em mídias digitais: questões para pensar gênero e visualidade no século $x \times I$

Este artigo apresenta reflexões teórico-metodológicas sobre possíveis abordagens sociológicas de imagens de feminilidade recorrentes na publicidade e em mídias digitais que circulam em redes sociais na internet. Problematizam-se as abordagens mais corriqueiras de imagens publicitárias do gênero feminino e sua relação com a noção de "representação" geralmente contraposta à "realidade”. Propõe-se uma abordagem diferenciada, que supere essa dicotomia e leve em conta o contexto atual de circulação de imagens em mídias digitais e novas tecnologias de comunicação, bem como as potenciais contribuições destas para constituir performances e referências identitárias de gênero.

Palavras-chave: Gênero; Feminilidade; Imagens; Consumo; Mídias digitais.

\section{Abstract}

Femininity and its imagens in digital media: questions to think gender and visuality in the $x \times I$ century

This paper presents theoretical and methodological considerations to possible sociological approachs on recurring images of femininity in advertising and digital media streaming in social networking sites. One problematizes the most common approaches to advertising images of female gender and its relations to the notion of "representation" usually contrasted with "reality." It is proposed a differentiated approach to overcome this dichotomy and take into account the present context of images flow through digital media and new communication technologies. At the same time, it takes in consideration the potential contributions of such media to constitute performances and identitary references of gender.

Keywords: Gender; Femininity; Images; Consumerism; Digital media.

Texto enviado em 16/9/2015 e aprovado em 7/7/2016. Dor: 10.11606/0103-2070.ts.2017.10 3981.

TÚlio CUNHa Rossi professor adjunto do Departamento de Ciências Sociais de Campos dos Goytacazes da Universidade Federal Fluminense (UFF) e professor colaborador do Programa de Pós-graduação em Ciências Sociais (PPGCS) da Universidade Federal do Maranhão (UFMA). Foi professor do Departamento de Sociologia e Antropologia da Universidade Federal do Maranhão (UFMA) de julho de 2014 a fevereiro de 2017. E-mail: tuliorossi@gmail.com. 